\title{
ORGANIZACIJOS IR DARBUOTOJO SOCIALINĖ ELGSENA: KLAUSIMYNO SUBSKALIŲ PATIKRA
}

\author{
Regina Andriukaitienė \\ Lietuvos sporto universitetas, Kaunas, Lietuva
}

\begin{abstract}
ANOTACIJA
Straipsnyje pristatomi tyrimo rezultatai yra viena iš sudedamujų „Vadybos kultūros lygio nustatymas siekiant igyvendinti socialiai atsakingos įmonès koncepciją“ tyrimo dalių. Pateikiamos tik klausimyno socialinio atsakingumo bloko skalių metodologinès kokybės charakteristikos. Tyrimo rezultatais buvo patvirtinta, kad organizacijos socialinès elgsenos ir darbuotojo socialinès elgsenos skalès gali būti naudojamos atsietai nuo vadybos kultūros dalies bloko klausimyne. Skaičiavimai rodo, kad klausimynas tinkamas įmonės pasirengimui tapti socialiai atsakinga nustatyti.
\end{abstract}

Raktažodžiai: organizacijos socialinè elgsena, darbuotojo socialinè elgsena, socialinis atsakingumas, įmonių socialinè atsakomybè.

\section{IVADAS}

Teorinis pagrindimas. Lietuva, tapusi ES nare ir prisidedama prie Lisabonos strategijoje suformuluoto tikslo - kurti konkurencingą ir dinamišką žiniomis pagrịstą ekonomiką, grindžiamą darnia ekonomine plètra, harmoningais santykiais tarp verslo, valdžios bei pilietinès visuomenès atstovu - igyvendinimo yra patvirtinusi ISA plètros viziją bei prioritetines jos igyvendinimo sritis (Astromskienè, Adamonienè, 2009). Organizacijos socialinis atsakingumas integruotai susijęs ir su organizacijos vadybos kultūra, kurią reprezentuoja tam tikri kriterijai: vadybos mokslo žinios ir gebejimas jas taikyti vadovavimo veiklose, savo vaidmens suvokimas organizacinejje ir socialinëje struktūrose, procesų organizavimas, asmeninè kultūra ir lyderiavimas. Visi šie veiksniai sudaro sąlygas socialiai atsakingai, su aplinka subalansuotai organizacijos elgsenai (Andriukaitienè, 2013). Pasak Ž. Simanavičienès, A. Simanavičiaus ir R. Kovaliovo (2012), imonėms, nusprendusioms ¿̇diegti i̇monių socialinès atsakomybès koncepciją, pirmiausia reikia nusistatyti prioritetines įmonių socialinès atsakomybės sritis: socialinę atsakomybę prieš darbuotojus, socialinę atsakomybę prieš vietos bendruomenę, socialinę atsakomybę prieš aplinką ir įmonès vertès didinimą. Autorių teigimu, imonių socialinę atsakomybę (toliau - ISA) diegiančios imonès turi suprasti, kad tik inovacijas diegiančios, aukštos kokybės produktus gaminančios ir geriausiai vartotojų poreikius tenkinančios įmonès gali tikètis, kad įdiegus İSA išaugs jų konkurencingumas ir vertė rinkoje visų pirma dėl teigiamo gyventoju požiūrio ir noro įsigyti jų prekes. V. Juščius ir A. Šneiderienè (2013) pabrèžia, kad ISA praktika padeda gauti ,visuomenès licenziją veikti“, atsižvelgti $\mathfrak{i}$ aplinkosauginius ir socialinius klausimus, sukurti sèkmès matavimo priemones, sustiprinti prekès ženklą, pagerinti imonès finansinę veiklą, pritraukti ir išlaikyti geriausius darbuotojus, padidinti našumą, pagerinti prekių ir paslaugu kokybę, išvengti teisinių pažeidimų, pritraukti kapitalą, išvengti visuomenès nepasitenkinimo. Kaip teigia R. Čiegis ir R. Norkutė (2012), dažniausiai i̇monių socialine atsakomybe domisi ir igyvendinti siekia didesnès organizacijos, vienijančios daugiau darbuotoju, taip pat teikiančios savo prekes ar paslaugas didesnei vartotojų rinkai. Todèl straipsnyje pristatomo empirinio tyrimo rezultatai atspindi didelès imonių grupès situaciją socialinio atsakingumo kontekste. 
Tyrimo objektas: klausimyno subskalių patikimumas.

Tyrimo tikslas: patikrinti organizacijos ir darbuotojo socialinès elgsenos klausimyno subskalių metodologines kokybès charakteristikas.

Tikslui pasiekti iškelti šie tyrimo uždaviniai: 1) aptarti įmonių socialinès atsakomybès teorinius aspektus; 2) pagrįsti klausimyno skaliu metodologinių kokybès charakteristiku patikimumą; 3) palyginti klausimyno skalių metodologines kokybės charakteristikas.

\section{METODIKA}

Empiriniam tyrimui atlikti buvo naudojamas straipsnio autorès suformuotas klausimynas „Vadybos kultūros vaidmuo socialinio atsakingumo kontekste“. Klausimynas sudarytas iš šešiu kategorijų: vadybinio personalo kultūra; valdymo procesų organizavimo kultūra; vadybos darbo sąlygu kultūra; dokumentacijos sistemos kultūra; organizacijos socialinė elgsena, darbuotojo socialinė elgsena. Vadybinès kategorijos sudarytos remiantis P. Zakarevičiumi (2003), kuris susistemino užsienio autorių (J. Galbraith, 1972; G. Dalton, 1970; K. Magnusen, 1977; H. Mintzberg, 1983; J. Pfeffer, 1975) darbus vadybos kultūros tematika. Socialinio atsakingumo kategorijos sudarytos išanalizavus L. Dagilienès (2010), I. Bučiūnienès, R. Kazlauskaitès (2012), V. Škudienès, V. Auruškevičienès (2012) ir kt. mokslo darbus.

Tyrimo metodai: mokslinès literatūros analizè, anketinė apklausa. Empiriniams duomenims apdoroti buvo taikomas faktorizavimo (pirminio ir antrinio) metodas psichometrinès charakteristikos skalių patikimumui nustatyti.

Tyrimo imtis. Tyrimo imti sudaro 1717 respondentu, pagal pareigybes atstovaujančiu visiems organizacijos darbuotojų sluoksniams.

Tyrimo organizavimas. Apklausa atlikta dvejose gamybinių imonių grupėse, kuriose tiriamuoju laikotarpiu dirbo 1915 darbuotoju (1030 ir 885). Dèl apklausos vykdymo pobūdžio ir terminų buvo derinama su įmonių grupès aukščiausio lygio vadovais. Empirinis tyrimas atliktas naudojant straipsnio autorès suformuotą klausimyną. Pirminis klausimyno tikrinimas buvo atliktas žvalgomojo tyrimo metu (Andriukaitienė, 2013), pasitelkus nedidelę respondentų imtí, atstovaujančią viešajam sektoriui. Šio tyrimo atveju pasirinktas privatus sektorius, siekiant patikrinti klausimyną kitoje erdvejje.

Klausimynas sudarytas iš dviejų blokų - socialinio atsakingumo ir vadybos kultūros. Šiame straipsnyje pristatomos tik socialinio atsakingumo bloko metodologinès kokybès charakteristikos. Socialinio atsakingumo blokas apima dvi skales: organizacijos socialinè elgsena ir darbuotojo socialinè elgsena. Organizacijos socialinès elgsenos subskalèse įtraukti teiginiai, atspindintys atsakomybès rinkoje, atsakomybès aplinkosaugoje, atsakomybès su darbuotojais ir visuomene situaciją. Darbuotojo socialinès elgsenos skalëje esantys teiginiai igalina nustatyti socialinès atsakomybės kritiką darbuotojų požiūriu, korupcijos, nepotizmo, favoritizmo užuomazgas, fizinės ir psichologinès darbuotojo savijautos aspektus, neapibrèžtumo ir informacijos stygiu bei ketinimus keisti organizaciją. Apklausa atlikta 2013 m. liepos-rugpjūčio mėnesiais. Tyrimo duomenys apdoroti SPSS (angl. Statistical Package for the Social Sciences) programa (21 versija). 


\section{TYRIMO REZULTATAI IR APTARIMAS}

Pirminio faktorizavimo metu išskiriama kriterijų visuma, o antrinio faktorizavimo metu išskirti kriterijai jungiami į skales. Iš 1 lentelès matyti, kad pagal Principal Components metodą faktoriniai svoriai svyruoja nuo 0,48 iki 0,84, o pagal Alpha factoring metoda - nuo 0,40 iki 0,83. Antrinio faktorizavimo rezultatai rodo, kad faktoriniai svoriai aukšti, taigi skalès yra patikimos, sudarytas klausimynas tinka numatytai požymių visumai matuoti.

1 lentelè. Organizacijos ir darbuotojo socialinès elgsenos faktorizavimas

\begin{tabular}{|c|c|c|}
\hline Klausimyno skalès ir subskalès & Pirminis faktorizavimas & Antrinis faktorizavimas \\
\hline \multicolumn{3}{|l|}{ Organizacijos socialinė elgsena } \\
\hline $\begin{array}{l}\text { Atsakomybė rinkoje (Vartotoju } \\
\text { informavimas, sveikata ir saugumas) }\end{array}$ & 0,84 & 0,81 \\
\hline Atsakomybè aplinkosaugoje & 0,82 & 0,78 \\
\hline $\begin{array}{l}\text { Atsakomybė santykiuose su } \\
\text { visuomene }\end{array}$ & 0,82 & 0,77 \\
\hline $\begin{array}{l}\text { Atsakomybė rinkoje (Paslaugos ir jų } \\
\text { kokybė) }\end{array}$ & 0,80 & 0,73 \\
\hline $\begin{array}{l}\text { Atsakomybė santykiuose su } \\
\text { darbuotojais }\end{array}$ & 0,75 & 0,66 \\
\hline Paaiškinta sklaida & $65,18 \%$ & $56,71 \%$ \\
\hline \multicolumn{3}{|l|}{ Darbuotojo socialinė elgsena } \\
\hline Ketinimai išeiti iš darbo & 0,83 & 0,83 \\
\hline $\begin{array}{l}\text { Neapibrėžtumas ir informacijos } \\
\text { stygius darbe }\end{array}$ & 0,81 & 0,60 \\
\hline $\begin{array}{l}\text { Fizinè ir psichologinè darbuotojo } \\
\text { savijauta }\end{array}$ & 0,81 & 0,74 \\
\hline $\begin{array}{l}\text { Socialinės atsakomybės kritika: } \\
\text { darbuotojų požiūris }\end{array}$ & 0,73 & 0,84 \\
\hline Korupcija, nepotizmas, favoritizmas & 0,78 & 0,72 \\
\hline Mano atsiliepimai apie organizaciją & 0,48 & 0,40 \\
\hline Paaiškinta sklaida & $53,63 \%$ & $47,82 \%$ \\
\hline
\end{tabular}

Klausimyno patikros rezultatai sugrupuoti pagal skales ir subskales. 2 lentelèje pateikti keturių subskalių, sudarančių organizacijos socialinès elgsenos skalę, patikros rezultatai. Subskalès apima nuo 5 iki 7 teiginių (iš viso skalëje yra 31 teiginys). Bendras paaiškintos sklaidos procentas šioje skalèje svyruoja nuo 43,36 iki 51,20, o Cronbach alpha koeficientas - nuo 0,74 iki 0,81. Spearman'o Brown'o reikšmès žemesnès už Cronbach alpha atitinkamai per 0,10-0,03 punkto.

Atsakomybės rinkoje (paslaugų ir jų kokybės požiūriu) subskalès aukštą patikimumo laipsni rodo tiek procentinè paaiškintos sklaidos išraiška (53,77 proc.), tiek Cronbach alpha koeficiento reikšmè - 0,81 (aukštas ir padidinto jautrumo, t. y. Spearman'o Brown'o koeficiento rodiklis - 0,78).

Žemiausia Cronbach alpha koeficiento reikšmè $(0,74)$ ir žemiausias paaiškintos sklaidos procentas $(43,36$ proc.) organizacijos socialinès elgsenos skalèje užfiksuota atsakomybès santykių su visuomene teiginiu subskalëje. Nors 2 lentelëje šie rodikliai yra žemesni, palyginti su kitais, tačiau statistikoje jie laikomi gana aukštais.

Paaiškinta faktoriaus sklaida - veiksnys, paveikiantis rezultatą, - negali būti mažesnis negu 10 proc. Jei paaiškinta faktoriaus sklaida mažesnè nei 10 proc., reikia ieškoti teiginio, kuris mažina sklaidą. Visų 1717 tyrime dalyvavusių respondentų aukščiausia paaiškinta faktoriaus sklaida yra 51,20 proc., tai reiškia, kad tik 51,20 proc. respondentų pritaria šiam faktoriui. 
2 lentelè. Organizacijos socialinès elgsenos subskalių metodologinès kokybės charakteristikos

\begin{tabular}{|c|c|c|c|c|c|c|c|c|c|c|}
\hline \multirow[t]{2}{*}{ Subskalès } & \multirow{2}{*}{$\begin{array}{c}\text { Teiginiu } \\
\text { skaičius } \\
\text { subskalëje }\end{array}$} & \multirow{2}{*}{$\begin{array}{l}\text { Paaiškinta } \\
\text { sklaida, } \\
\text { proc. }\end{array}$} & \multirow{2}{*}{$\begin{array}{c}\text { Cronbach } \\
\text { alpha } \\
\text { koeficientas }\end{array}$} & \multirow{2}{*}{$\begin{array}{l}\text { Spearman'o- } \\
\text { Brown'o } \\
\text { koeficientas }\end{array}$} & \multicolumn{3}{|c|}{$\begin{array}{l}\text { Faktorinis svoris } \\
\text { (L) }\end{array}$} & \multicolumn{3}{|c|}{$\begin{array}{l}\text { Vieneto visumos } \\
\text { koreliacija (r/itt) }\end{array}$} \\
\hline & & & & & mean & $\min$ & $\max$ & mean & $\min$ & $\max$ \\
\hline $\begin{array}{l}\text { Atsakomybè } \\
\text { rinkoje } \\
\text { (Paslaugos ir } \\
\text { jų kokybė) }\end{array}$ & 6 & 51,20 & 0,81 & 0,78 & 0,71 & 0,65 & 0,79 & 0,50 & 0,30 & 0,78 \\
\hline $\begin{array}{l}\text { Atsakomybè } \\
\text { rinkoje } \\
\text { (Vartotojų } \\
\text { informavimas, } \\
\text { sveikata ir } \\
\text { saugumas) }\end{array}$ & 5 & 50,26 & 0,75 & 0,67 & 0,71 & 0,66 & 0,76 & 0,49 & 0,29 & 0,76 \\
\hline $\begin{array}{l}\text { Atsakomybė } \\
\text { aplinkosaugoje }\end{array}$ & 7 & 44,40 & 0,79 & 0,72 & 0,66 & 0,59 & 0,72 & 0,43 & 0,19 & 0,71 \\
\hline $\begin{array}{l}\text { Atsakomybe } \\
\text { santykiuose su } \\
\text { darbuotojais }\end{array}$ & 7 & 44,57 & 0,79 & 0,74 & 0,66 & 0,55 & 0,73 & 0,43 & 0,23 & 0,73 \\
\hline $\begin{array}{l}\text { Atsakomybè } \\
\text { santykiuose su } \\
\text { visuomene }\end{array}$ & 6 & 43,36 & 0,74 & 0,64 & 0,66 & 0,55 & 0,75 & 0,41 & 0,18 & 0,73 \\
\hline
\end{tabular}

Analizuojant darbuotojo socialinės elgsenos skalès metodologines kokybės charakteristikas reikia pabrèžti, kad šią skalę sudaro šešios subskalès, apimančios 41 teigini. Subskalių teiginių skaičius yra pasiskirstęs gana netolygiai, tačiau iš 3 lentelès matyti, kad rezultatams tai akivaizdžios itakos neturi, išskyrus subskalę „Mano atsiliepimai apie organizaciją“. Subskalès „Mano atsiliepimai apie organizaciją“ Cronbach alpha koeficientas yra gana žemas - 0,62, o Spearman'o Brown’o koeficiento neįmanoma apskaičiuoti, kai teiginių skaičius yra mažesnis nei 5.

3 lentelè. Darbuotojo socialinès elgsenos subskalių metodologinės kokybès charakteristikos

\begin{tabular}{|c|c|c|c|c|c|c|c|c|c|c|}
\hline \multirow[t]{2}{*}{ Subskalès } & \multirow{2}{*}{$\begin{array}{l}\text { Teiginiú } \\
\text { skaičius } \\
\text { subskalèje }\end{array}$} & \multirow{2}{*}{$\begin{array}{l}\text { Paaiškinta } \\
\text { sklaida, } \\
\text { proc. }\end{array}$} & \multirow{2}{*}{$\begin{array}{c}\text { Cronbach } \\
\text { alpha } \\
\text { koeficientas }\end{array}$} & \multirow{2}{*}{$\begin{array}{l}\text { Spearman'o- } \\
\text { Brown'o } \\
\text { koeficientas }\end{array}$} & \multicolumn{3}{|c|}{$\begin{array}{l}\text { Faktorinis svoris } \\
\text { (L) }\end{array}$} & \multicolumn{3}{|c|}{$\begin{array}{l}\text { Vieneto visumos } \\
\text { koreliacija (r/itt) }\end{array}$} \\
\hline & & & & & mean & $\min$ & $\max$ & mean & $\min$ & $\max$ \\
\hline $\begin{array}{l}\text { Ketinimai išeiti } \\
\text { iš darbo }\end{array}$ & 6 & 59,59 & 0,86 & 0,84 & 0,77 & 0,70 & 0,80 & 0,59 & 0,42 & 0,80 \\
\hline $\begin{array}{l}\text { Neapibrěžtumas } \\
\text { ir informacijos } \\
\text { stygius darbe }\end{array}$ & 6 & 49,26 & 0,79 & 0,72 & 0,70 & 0,64 & 0,75 & 0,48 & 0,30 & 0,74 \\
\hline $\begin{array}{l}\text { Fizinè ir } \\
\text { psichologinè } \\
\text { darbuotojo } \\
\text { savijauta }\end{array}$ & 5 & 58,03 & 0,82 & 0,77 & 0,76 & 0,68 & 0,80 & 0,57 & 0,32 & 0,79 \\
\hline $\begin{array}{l}\text { Mano } \\
\text { atsiliepimai apie } \\
\text { organizaciją }\end{array}$ & 4 & 43,55 & 0,62 & - & 0,65 & 0,38 & 0,86 & 0,52 & 0,22 & 0,77 \\
\hline $\begin{array}{l}\text { Korupcija, } \\
\text { nepotizmas, } \\
\text { favoritizmas }\end{array}$ & 10 & 36,61 & 0,80 & 0,74 & 0,59 & 0,36 & 0,72 & 0,34 & 0,05 & 0,70 \\
\hline $\begin{array}{l}\text { Socialinės } \\
\text { atsakomybès } \\
\text { kritika: } \\
\text { darbuotojų } \\
\text { požiūris }\end{array}$ & 10 & 43,27 & 0,85 & 0,79 & 0,66 & 0,57 & 0,72 & 0,42 & 0,23 & 0,71 \\
\hline
\end{tabular}


Lyginant organizacijos socialinès elgsenos ir darbuotojo socialinės elgsenos subskalių metodologines kokybès charakteristikas (2 ir 3 lentelès) matyti, kad organizacijos socialinès elgsenos skalès koeficientų reikšmès yra šiek tiek aukštesnès, tačiau skirtumas gana nedidelis. Paaiškintos faktoriaus sklaidos procentas abejose skalèse viršija žemiausią ribą bent tris kartus, taigi akivaizdu, kad respondentų pritarimas išskirtiems faktoriams yra didelis.

Maksimalus Cronbach alpha lygus 1. Gautos didelès Cronbach alpha reikšmès leidžia teigti, kad socialinio atsakingumo skalèse ittrauktų i klausimyną subskalių teiginiai yra glaudžiai susiję. Minimalus faktorinis svoris (L) negali būti žemesnis negu 0,3, o jeigu jis yra žemesnis, vadinasi, subskalèje yra netinkamas teiginys. Lyginant minimalias faktorinio svorio reikšmes abejose skalèse matyti, kad žemiausias faktorinis svoris, t. y. 0,36, užfiksuotas tik vienoje subskalëje.

Vieneto visumos koreliacija rodo, kiek klausimyno teiginiai koreliuoja su išskirta subskale. Jei vieneto visumos koreliacijos r/itt vidurkis yra mažesnis už 0,2 , tai rodo, kad kažkuris teiginys nelabai tinka priskirtai subskalei. Organizacijos socialinès elgsenos subskalèse minimali vieneto koreliacija yra nuo 0,41 iki 0,50, o darbuotojo socialinès elgsenos subskalèse - nuo 0,34 iki 0,59. Tai rodo, kad klausimyno teiginiai koreliuoja su išskirtomis subskalėmis.

\section{IŠVADOS}

1. Aptarus esminius imonių socialinès atsakomybès teorinius apsektus teigtina, kad organizacijų socialinis atsakingumas yra visuomenès vystymosi dimensija, praktikoje iprasminanti vertybes, kuriomis grindžiama organizacijų ir visuomenès santykių darnos percepcija.

2. Nustatyta, kad organizacijos socialinès elgsenos ir darbuotojo socialinès elgsenos skalès gali būti naudojamos atsietai nuo vadybos kultūros dalies bloko klausimyne. Tyrimo rezultatais patvirtintas klausimyno tinkamumas imonès pasirengimui tapti socialiai atsakinga nustatyti.

3. Palyginus klausimyno subskalių metodologines kokybės charakteristikas nustatyta, kad abi socialinio atsakingumo skalès atitinka patikimumo ir validumo reikalavimus, esminių skirtumų tarp šių skalių kokybès charakteristikų nepastebèta.

\section{LITERATŪRA}

1. Andriukaitienè, R. (2013). Vadybos kultūros ir socialinio atsakingumo sąsajos savivaldos organizacijoje. Management Theory and Studies for Rural Business and Infrastructure Development, 35 (3), 339-346.

2. Astromskienè, A., Adamonienè, R. (2009). Imonių socialinès atsakomybès iniciatyvų Lietuvoje tendencijos. Ekonomika ir vadyba (Economics \& Management), 14, 217-223.

3. Bučiūnienè, I., Kazlauskaitè, R. (2012). The linkage between HRM, CSR and performanceoutcomes. Baltic Journal of Management, 7 (1), 5-24.

4. Čiegis, R., Norkutè, R. (2012). Lietuvos banku socialinė atsakomybė darnaus vystymosi kontekste. Management of Organizations: Systematic Research (Organizaciju vadyba: sisteminiai tyrimai), 63, 19-33.

5. Dagilienè, L. (2010). The Research of Corporate Social Responsibility Disclosures in Annual Reports. Inzinerine Ekonomika-Engineering Economics, 21 (2), 197-204. 
6. Dalton, G. (1970). Organizational Structure and Design. Whitby: Richard D. Irwin.

7. Galbraith, J. R. (1972). Organization design: An information processing view. In J. W. Lorsch and P. R. Lawrence (Eds.), Organization Planning. Homewood, Illinois: Irwin-Dorsey.

8. Juščius, V., Šneiderienè, A. (2013). Imonès socialinès atsakomybès įtaka regioninei plètrai. Regional Formation and Development Studies, 1 (9), 66-78.

9. Magnusen, K. O. (1977). Organizational design, development and behaviour: a situational view. Glenview: Scoot Foresman and CO.

10. Mintzberg, H. (1983). Structure in fives: Desigining Effective Organizations. Englewood Cliffs, NJ: Prentice-Hall.

11. Pfeffer, J. (1975). Organizational Design. AHM Pub. Co.

12. Simanavičienè, Ž., Simanavičius, A., Kovaliov, R. (2012). İmonių socialinès atsakomybès matavimo galimybès. Ekonomika ir vadyba (Economics and Management), 17 (4), 1528-1534.

13. Škudienè, V., Auruškevičienè, V. (2012). The contribution of corporate social responsibility to internal employee motivation. Baltic Journal of Management, 7 (1), $49-67$.

14. Zakarevičius, P. (2003). Pokyčiai organizacijose: priežastys, valdymas, pasekmès. Kaunas: VDU leidykla. 


\title{
SOCIAL BEHAVIOUR OF ORGANIZATION AND EMPLOYEE: VERIFICATION OF QUESTIONNAIRE SUBSCALES
}

\author{
Regina Andriukaitienė \\ Lithuanian Sports University, Kaunas, Lithuania
}

\begin{abstract}
Theoretical substantiation. Lithuania, as an EU member contributing to the Lisbon strategy, aims at building a competitive and dynamic knowledge-based economy, grounded on sustainable economic development, harmonious relations between business, government and civil society. It has approved CSR development vision and development as well as implementation of its priority areas (Astromskiene, Adamoniene, 2009). Social responsibility of the organization is also integrally linked with the organization's management culture represented by the criteria such as scientific knowledge management, the ability to apply leadership activities, perception of its own role in organizational and social structures, the organization of processes, personal culture and leadership. These are the factors which provide conditions for socially responsible, environmentally sustainable organizational behavior (Andriukaitiene, 2013). According to Z. Simanaviciene, A. Simanavicius and R. Kovaliov (2012), companies that decide to implement the concept of corporate social responsibility first need to define the priority of the area of corporate social responsibility: social responsibility to employees, social responsibility to the local community, social responsibility to the environment and expansion of the company's value. According to the authors, companies implementing the company's social responsibility (hereinafter CSR) have to understand that only innovative, high-quality producing and the best consumer-oriented companies can expect to increase their competitiveness and market value after implementing CSR, in particular regarding the positive attitude of the population and willingness to buy their products. V. Juscius and A. Sneideriene (2013) highlight that CSR practice helps to obtain "the public license to operate", take into account environmental and social issues, create success measurement tools, enhance the brand, improve the company's financial activities, attract and retain the best employees, increase productivity, improve the quality of goods and services, avoid legal violations, raise capital, avoid public discontent. According to R. Ciegis and R. Norkute (2012), larger organizations uniting more employees as well as providing their goods or services to a greater consumer market are interested in and aim to implement company's social responsibility.
\end{abstract}

The object of the survey was the reliability of the questionnaire subscales.

The aim of study was to verify the organization's and the employee's social behaviour questionnaire subscales and their methodological characteristics.

The following research objectives were set to achieve the aim: 1) to discuss theoretical aspects of the corporate social responsibility; 2) to validate the reliability of scales and their methodological characteristics; 3 ) to compare the methodological characteristics of the questionnaire scales

Methods Scientific literature analysis and questionnaire survey methods were used. These methods were used for empirical data processing: factorization (primary and secondary), psychometric characteristics for the determination of the reliability of scales. The study sample consisted of 1717 respondents representing all layers of the organization's staff according to the positions. The survey was conducted in two industrial company groups with 1915 employees in total (1030 and 885 employees) during the study period. The survey nature and terms were combined with the group of companies' senior management. The empirical study was conducted using article author's developed questionnaire. The survey carried out in 
July - August of 2013. The study data was processed using SPSS (Statistical Package for the Social Sciences) programme (Version 21).

Findings. Results of this study are one of the constituent parts of the research "Establishment of management culture level in order to implement the concept of a socially responsible company". Only the methodological characteristics of the social responsibility unit scales of the questionnaire are provided in this article. The study results confirmed that the organization's social behaviour and employees' social behaviour scales can be used separately from the management culture block in the questionnaire. Both social responsibility scales matched reliability and validation requirements and no significant differences between the quality characteristics of these scales were observed. The calculations show that the questionnaire is adequate to diagnose the company's readiness to become socially responsible.

Keywords: organization's social behaviour, employees' social behaviour, social responsibility, corporate social responsibility. 


\section{СОЦИАЛЬНОЕ ПОВЕДЕНИЕ ОРГАНИЗАЦИИ И РАБОТНИКА: ПРОВЕРКА ПОДШКАЛ ОПРОСНИКА}

\section{Регина Андрюкайтене}

Литовский университет спорта, Каунас, Литва

\section{РЕЗЮМЕ}

Теоретическое обоснование. Литва, ставшая членом ЕС и присоединившаяся к реализации цели Лиссабонской стратегии - строить конкурентноспособную, динамичную, основанную на знаниях экономику на основе устойчивого экономического развития, гармоничных отношений между предпринимательством, правительством и представителями гражданского общества - подтвердила визию развития корпоративной социальной ответственности (КСО) и приоритетные направления ее реализации (Astromskienė, Adamonienė, 2009).

КСО имеет итегрированную связь с культурой менеджмента организации, которую представляют такие критерии, как знания в области науки менеджмента и умение их применять в руководящей деятельности, восприятие своей роли в организационной и социальной структурах, организация процессов, личная культура и лидерство. Все эти факторы способствуют социально ответственному, со средой сбалансированному поведению организации (Andriukaitienė, 2013). Согласно мнению Ж. Симанавичене, А. Симанавичюса и Р. Ковалева (Simanavičienė, Simanavičius, Kovaliovas, 2012), организации, решившие внедрить концепцию КСО, в первую очередь должны определить приоритетные направления еe развития: социальная ответственность перед сотрудниками, социальная ответственность перед местным сообществом, социальная ответственность по отношению к окружающей среде и увеличение стоимости предприятия. По мнению авторов, предприятия, внедряющие КСО, должны понимать, что только внедряя инновации, производя высококачественную продукцию и лучше всех удовлетворяя потребности пользователей, могут повысить свою конкурентноспособность и рыночную стоимость в первую очередь за счет положительного отношения населения и его желания покупать их товары. В. Ющюс и А. Шнейдерене (Juščius, Šneiderienè, 2013) подчеркивают, что в практике КСО помогает получить у общества «лицензию действовать», учитывать социальные вопросы и вопросы охраны окружающей среды, создать инструменты измерения успеха, укреплять знак товара, улучшать финансовую деятельность, привлекать и удержать лучших работников, повышать производительность труда, улучшать качество товаров и услуг, привлечь капитал, избежать правовых нарушений и недовольства общества. По словам Р. Чегиса и Р. Норкуте (С̌iegis, Norkutè, 2012), чаще всего КСО интересуются и стремятся ее реализовать крупные организации, объединяющие большее число работников, а также оранизации, обеспечивающие товаром или услугами более широкий круг потребителей.

Объект исследования - надежность субшкал опросника.

Цель исследования - проверить методологические характеристики качества субшкал опросника о социальном поведении организации и работника. Для достижения цели были поставлены следующие задачи исследования:

1) обсудить теоретические аспекты корпоративной социальной ответственности;

2) обосновать надежность методологических характеристик качества шкал опросника;

3) сравнить методологические характеристики качества шкал опросника. 
Методика. Применялись методы анализа научной литературы и анкетирования. Для оброботки эмпирических данных были использованы следующие методы: первичная и вторичная факторизация для определения надежности психометрических характеристик шкал. Объем исследования - 1717 респондентов, по обязанностям представляющих все слои работников организации. Опрос проводился в двух групах производственных предприятий, в которых в период опроса работали 1915 работников (1030 и 885). Характер и термины опроса были соглосованны с руководителями высшего уровня. В эмпирическом исследовании был использован инструмент опроса, созданный автором статьи. Опрос проводился в июле-августе 2013 года. Данные опроса были обработаны с помощью программы SPSS (версия 21).

Результаты. Результаты настоящего исследования являются одной из составных частей исследования «Установление уровня культуры менеджмента в целях реализации концепции социально ответственного предприятия». Предоставляются методологические характеристики только блока шкал социальной ответственности. Результаты исследования показали, что в опроснике шкала социального поведения организации и шкала социального поведения работника могут быть использованы отдельно от блока шкал культуры менеджмента. Обе шкалы социальной ответственности соответствуют требованиям надежности и валидности. Основных различий между методологическими характеристиками этих шкал не наблюдалось.

Расчеты показали, что инструмент опроса подходит для диагностики готовности предприятия стать социально ответственной организацией.

Ключевые слова: социальное поведение организации, социальное поведение работника, социальная ответственность, корпоративная социальная ответственность. 